\title{
La globalización en el Derecho Internacional
}

Antonio Parra Gil

Si bien el Diccionario de la Lengua Española define el neologismo globalización como la tendencia de los mercados y de las empresas a extenderse, alcanzando una dimensión mundial que sobrepasa las fronteras nacionales, ${ }^{1} \mathrm{el}$ término mundialización (mondialisation) en lugar de globalización, usado en idioma francés, tal como lo recuerda el Dr. Rodrigo Borja Cevallos en su Enciclopedia de la Política, ${ }^{2}$ es más apropiado.

Denis Duclos manifiesta, en un estupendo artículo publicado en Le Monde Diplomatique, ${ }^{3}$ que es universal lo que es común a todos los seres humanos, se extiende sobre toda la superficie de la tierra y concieme a todo el mundo, y que la actual mundialización económica se presenta como un nuevo proyecto de vocación universal.

Dentro del concepto indicado, esto es como lo universal, que es común a todos, el Derecho Internacional es una ciencia globalizada, universal por su propia naturaleza.

La comunidad internacional existe desde el momento que sus miembros toman conciencia jurídica de su solidaridad y tienen la voluntad de someter sus relaciones a reglas comunes; y el Derecho Internacional existe porque existe la comunidad internacional. Se origina en ella, que es una sociedad de agrupaciones humanas (Estados) y de asociaciones intergrupales que crea o produce un derecho -su propio derecho - para regir las relaciones entre las agrupaciones y asociaciones a que esa situación da lugar, esto es un derecho producto de una conciencia colectiva, que acepta ciertas normas de conducta que se convierten en jurídicas (normas jurídicas) por su carácter obligatorio.

Esas normas de conducta adquieren carácter obligatorio por decisión (la voluntad) de la comunidad total, que trasciende la voluntad del Estado. Es, sin duda, una voluntad conjunta y solidaria de lo que algunos tratadistas han calificado como el conglomerado social internacional, que acepta como válidas y obligatorias determinadas normas de conducta para que rijan las relaciones internacionales, que se sustenta en el convencimiento o criterio general de justicia, bien común (o interés de grupo) y en la cooperación, que prima en la comunidad internacional.

Esa comunidad internacional, de carácter universal, que se ha formado al correr de los siglos, y que poco a poco ha creado su propio derecho, con normas a las que deben sujetarse las relaciones entre sus miembros, es producto del instinto de asociación del hombre; del desarrollo científico y tecnológico (grandes descubrimientos desarrollo de la imprenta; renacimientos de las ciencias y las artes, etc., etc.); de la interpretación y estudio del ser humano y de la existencia y desarrollo de los grupos humanos (la antropo- logía y la sociología); y del imperativo de cooperación, del comercio y de la seguridad colectiva o seguridad internacional (Estados, especialmente los pequeños, que confian su seguridad al orden internacional).

Los profesores Scelle, Fauchille, Holtzendorff y Jitta, entre otros, participan del criterio expuesto. Para Fauchille, el fundamento del Derecho Internacional estriba en el hecho innegable y necesario de que existe, entre los Estados que han alcanzado o sobrepasado cierto nivel de civilización, una comunidad permanente y jurídicamente reconocida.

Este planteamiento, muy general, que explica el carácter universal o global del Derecho Internacional, no impide ni se contrapone a que esta ciencia atienda la psicología especial de los pueblos y las características propias de las distintas nacionalidades o principio de las nacionalidades, ${ }^{4}$ y que admita regionalismos jurídicos, como es el caso del Derecho Internacional Americano.

La universalidad del Derecho Internacional Público la encontramos desde sus inicios en las civilizaciones anteriores a Grecia y Roma, en el mundo civilizado de entonces; en la paz Romana, consecuencia del orden impuesto por el Imperio (paz impuesta en la época de Octavio Augusto o paz Octaviana); en las luminosas explicaciones del insigne dominico Francisco de Vitoria, el doctor sorbónico, que dio gloria al claustro universitario de la milenaria Salamanca desde la cátedra Prima y sus célebres Relectione Theologicae, en especial De Indis (la quinta) y De iure belli (la sexta), en que define el Derecho de Gentes; en el De legibus ac Deo legislatore del célebre teólogo español Francisco Suárez, en el que expone su inimitable doctrina relativa a la comunidad de derecho entre los pueblos y a la formación de un Derecho de Gentes natural y positivo, generado éste en la costumbre; en el holandés Hugo Groccio, con su De iure belli ac pacis, que sistematizó el Derecho de Gentes de su época; en el Maestro Soto (De iustitia et de jure); y en un sinnúmero de otros egregios teólogos, canonistas, juristas e historiadores.

El proceso de globalización, mundialización o universalización del Derecho Internacional también lo encontramos en Acuerdos, Convenciones, Congresos, Alianzas, Asociaciones y Academias, entre las que sobresalen, a título de ejemplo, el Congreso de Westfalia (1648), considerado como punto de referencia importante del Derecho Internacional moderno que puso fin a la guerra de los treinta años, nacida de la confrontación entre católicos y protestantes, por lo que en Onsabrück Suecia negociaba con los protestantes, y Francia con los católicos en Müster; mientras terminaba la época de los etnarcas y se eliminaban los 
ordenamientos jurídicos superiores $e$ inferiores de la alta Edad Media; la Santa Alianza (1815); el Congreso de Viena (1814 - 1815); las Conferencias de La Haya (1899 y 1907), que tratan de la solución pacífica de las controversias internacionales, resaltando la supremacía del derecho sobre la fuerza; la Conferencia de 1904, promovida por Teodoro Roosevelt, presidente de los Estados Unidos de América; la creación de la Academia de Derecho Internacional de La Haya (1921); la Fundación Carneggie para la Paz Internacional; el Instituto de Derecho Internacional, etc.

Poco a poco se perfeccionan los principios y normas básicas de esa relación entre Estados independientes, sustentada en la representación permanente por medios de agentes diplomáticos que buscan un equilibrio entre intereses muchas veces contrapuestos, a base del respeto a su independencia y a su integridad territorial; la no intervención en sus asuntos internos; la igualdad soberana; la distinción entre mar territorial y alta mar o mar libre; la libertad de navegación y de tránsito; el concepto de ríos internacionales y de riquezas compartidas, que poco a poco llevó a la codificación del Derecho Internacional (Derecho de los Tratados; Derecho del Mar, etc.)

La Organización de las Naciones Unidas y la Carta de las Naciones Unidas, con sus organismos, resoluciones convenciones y acuerdos, es un eslabón importante de la universalización del Derecho Internacional.

La Carta de las Naciones Unidas tiene como principio fundamental el mantenimiento de la paz y de la seguridad internacional, pilares fundamentales de esa Organización, a más de otros principios y normas, todos con carácter de jus cogens, como los de igualdad soberana de los Estados; la buena fe en el cumplimiento de los acuerdos y convenciones; la solución pacífica de las controversias internacionales; la obligación de abstenerse del uso o amenaza de uso de la fuerza contra la integridad territorial o la independencia política de cualquier Estado, o en cualquier otra forma incompatible con los propósitos de las Naciones Unidas; la no intervención en asuntos de jurisdicción interna de los Estados, propósitos y principios que son de aplicación general tanto a los Estados Miembros como a los Estados no Miembros de la Organización de las Naciones Unidas, tal como consta y se deduce del párrafo 6 del artículo 2;6 de los artículos $11^{7}$ y $32^{8}$, del párrafo 2 del artículo $35,{ }^{\circ}$ y de los artículos $50^{10}$ y 93 de la Carta de las Naciones Unidas."

Conforme al indicado párrafo 6 del artículo 2 de la Carta de la Organización de las Naciones Unidas (La organización hará que los Estados que no son Miembros de las Naciones Unidas se conduzcan de acuerdo con estos principios en la medida que sea necesaria para mantener la paz y la seguridad internacional), ésta puede actuar respecto de los Estados no Miembros cuando son parte de situaciones que pueden afectar la paz y la seguridad internacional; 12 principio que ha sido invocado tanto en el Consejo de Seguridad como en la Asamblea General, entre otras muchas situaciones, en el caso español (petición de Polonia); en el litigio del estrecho de Corfú; Bulgaria y Hungría, por derechos humanos; etc, etc. ${ }^{13}$

El profesor Ahmed Mahiou, al comentar el parágrafo 6 del artículo 2 de la Carta de las Naciones Unidas, manifiesta que cada vez se hace menos diferenciación entre Estados Miembros y no Miembros, usando expresiones que involu- cran ambas situaciones, tales como todos los Estados, todas las naciones, todos los Estados y todas las autoridades, las partes interesadas, etc. ${ }^{14}$

Son trascendentales las transformaciones sociales originadas por el avance de la ciencia y la tecnología, especialmente en el campo de las comunicaciones ${ }^{15}$ y en la explotación de los recursos naturales, que tienen que enfrentar una peligrosa explosión demográfica; las migraciones de poblaciones empobrecidas; las pandemias que arrasan con poblaciones enteras, especialmente en el África subsahariana; la defensa del medio ambiente, etc., que están interrelacionadas e inciden en el derecho. ${ }^{16}$

La globalización o mundialización, realidad económica y política, suscita cuestionamientos en diversos campos del derecho, originado en conflictos con el Estado de Derecho o el sometimiento de todos los actores sociales a la jurisdicción nacional, a base de la primacía del derecho (la legalidad del Estado y la Nación), como expresión asociada a los derechos fundamentales, amparado en la efectividad del Estado - Nación, en la que el ciudadano - que pertenece a una comunidad política de iguales, y a una comunidad nacional, en la que todos tienen la misma cultura, hablan el mismo idioma, practican la misma religión y veneran la misma historia- goza de derechos y participa en el proceso gestor del Estado.

Estos conflictos (mundialización económica, financiera y de mercados con el Estado de Derecho), que se originan o causan que este fenómeno (la globalización) sobrepase los conceptos del Estado - Nación, soberanía y fronteras, requieren una nueva legalidad. En otras palabras, la realidad económica y política de la globalización o mundialización requiere una nueva realidad jurídica, acorde con ella, que se asocie con esas transformaciones, ${ }^{17}$ porque escapan, como dice Grün, al control del Estado, realidad territorial con la desterritorialización de la riqueza, el poder y la información, superando o situándose por sobre las fronteras económicas.

Para Anthony Giddens, sucesor de Karl Popper en la dirección del London School of Economics, la globalización debe estar vinculada a un derecho internacional, al fomen to de normas universales de derechos humanos y a una acción concertada para afrontar algunos de los conflictos que ha ocasionado, pero sin olvidar que lo global no es sólo una serie de conexiones económicas, ya que también ha habido un gran desarrollo del derecho internacional y del protagonismo de las organizaciones no gubernamentales (ONG) y de integración de valores.

El Estado - Nación, que también se caracteriza por el poder coercitivo concentrado en sus órganos de poder se enfrenta hoy a lo que algunos califican como desjerarquización del concepto de Estado Nacional como consecuencia, por un lado, de la aparición de entidades supranacionales gubernamentales y no gubernamentales, ... y por el otro de fortalecimiento de centros de poder internacionales que, en definitiva es, como dice Walter Goodbar, citado por Emesto Grün, una de las consecuencias imprevistas de la globalización.

La crisis del Estado - Nación repercute directamente en el concepto de soberanía, ligado al Estado, que ha perdido mucho de su significado porque estamos en vías de pasar de Estados a comunidades económicas (Simón Pers), transformación que lleva a la supremacía de las normas su- 
pranacionales (de organismos regionales y universales) sobre las nacionales, como es el caso de los organismos regionales, que también influyen y afectan el rol del Estado. ${ }^{18}$

El concepto de soberanía como la potestad jurisdiccional del Estado, dictando y derogando leyes, identificada con la voluntad del Estado, ${ }^{19}$ independiente de cualquier otro poder, característica del Estado centralizado, ha sido alterado por los fenómenos de la mundialización, especialmente en los campos de las finanzas, el comercio, los mercados, incluyendo a los grupos regionales o de integración económica, consecuencia del importante desarrollo tecnológico, fenómeno que se expresa, tal como lo afirma el Dr. Rodrigo Borja Cevallos, en la apertura de mercados, en el comercio libre, en el flujo internacional de capitales, en la formación de amplias zonas de libre intercambio, la eliminación de barreras arancelarias y no arancelarias, la integración de grandes bloques económicos, ... en la que el capital ha encontrado su propia soberanía, y es libre de moverse internacionalmente y elige el Estado en que quiere trabajar, sin que el Estado pueda evitarlo, perdiendo así el control frente al capital globalizado. ${ }^{20}$

Este fenómeno (la globalización o mundialización), que sobrepasa la voluntad del Estado, requiere que el Derecho Internacional encuentre formulas que permitan la implementación de normas que lo regulen y que respeten la voluntad del Estado, su soberanía, sus intereses, dentro del orden jurídico de la comunidad internacional, cuyos miembros primarios son los Estados soberanos, independientes e iguales, que lleva implícito el respeto, la coexistencia y la reciprocidad, a base de aplicar las normas y los principios por ellos aceptados, ${ }^{21}$ esto es la aprobación necesaria de la relación del Estado con la comunidad internacional, de la que es miembro, que se sustenta, en última instancia, en que la eficacia del Derecho Internacional está fundada en la voluntad común de los Estados, y en la validez de los principios jurídicos que en su conjunto forman el Derecho Internacional.

La globalización o mundialización no sólo se identifica con los avances tecnológicos y científicos, especialmente en las comunicaciones, que permiten los intercambios financieros y comerciales destinados a conseguir la implantación del libre mercado, que tienen como efecto la interdependencia, sino también con el Derecho Internacional, que regula situaciones conflictivas y de cooperación, originadas o producidas por ese fenómeno económico y social, que muchos rechazan, con razón, por las injusticias implícitas del libre mercado, producto del capitalismo salvaje, y luchan por la implantación de una radical reorientación de los objetivos del comercio hacia la justicia social y la definición de normas y valores aplicables a políticas comerciales y una democratización de las instituciones internacionales en nombre de todas las partes afectadas (comercio justo, con tratamiento preferencial o de excepción para los países subdesarrollados, que contemple un ajuste equitativo de los precios) y que mediante Tratados no comerciales se puede equilibrar la agenda liberalizadora, aplicada por la Organización Mundial del Comercio (pero no limitada a ella) para dar prioridad a objetivos sociales y ambientales, y citan como ejemplo la Convención sobre Biodiversidad (con su Protocolo de Bioseguridad de Cartagena) y la Convención sobre Cambio Climático (y su Protocolo de Kioto), insistiendo que para ello debe fortalecerse el respeto de los derechos humanos (abuso contra los derechos humanos, torturas, crímenes de guerra, actividades delictivas transnacionales, tráfico de personas, tráfico ilícito de drogas) y las libertades fundamentales, incluido el derecho al desarrollo, y lograr así un efectivo y real funcionamiento de la economía mundial ${ }^{22}$ y la lucha contra los delitos internacionales mediante la institucionalización de los órganos coercitivos o de justicia supranacionales.

Para efecto de la lucha contra los delitos que se considera que afectan al orden internacional o que atentan gravemente contra los derechos humanos y el derecho humanitario, existen, al decir de la Alta Comisionada de las $\mathrm{Na}-$ ciones Unidas para los Derecho Humanos, dos medios importantes y complementarios para la implementación de la jurisdicción penal internacional: el enjuiciamiento a cargo de Tribunales Penales Internacionales y la aplicación doméstica del principio de jurisdicción universal, que se basa, el uno, (los Tribunales Penales Internacionales) en la creación de la Corte Penal Internacional (Estatuto de Roma, 1998), auténtica globalización de la justicia penal, con competencia para juzgar crímenes de trascendencia internacional de carácter complementario a las jurisdicciones nacionales, esto es que ejerce su competencia en los casos que los Estados no puedan o no quieran juzgar a los responsables de crímenes horrendos, conforme a las reglas que establece el Estatuto, que conllevan responsabilidad penal; y el otro (principio de la jurisdicción universal), en la noción de que ciertos crímenes son tan dañinos para los intereses internacionales, que los Estados pueden - $e$ incluso están obligados a - incoar procedimientos contra los perpetradores, independientemente del lugar de comisión del crimen o de la nacionalidad del perpetrador o de la víctima, ${ }^{23}$ principio que está considerado, según la misma funcionaria internacional, por la Corte Internacional de Justicia en el caso que se está sustanciando sobre la orden de captura contra el Ex Ministro de Asuntos Exteriores de la República Democrática del Congo, dictada por un Juez de instrucción belga. ${ }^{24}$

La violación a los derechos humanos subsistirá mientras subsista la amplia brecha que separa los países ricos de aquellos en vías de desarrollo (Mary Robinson, Alta Comisionada de las Naciones Unidas para los Derechos Humanos).

Son muy complejos y difíciles los problemas que la globalización plantea al Derecho Internacional, que contemplan a más de los ya esbozados, el de la contaminación del medio ambiente y el de las migraciones, que tiene, según Stephen Castle, especial importancia en las transformaciones sociales contemporáneas, y que afectan las relaciones sociales, culturales, políticas e internacionales, las estructuras económicas y los derechos fundamentales de la persona, así como la identidad nacional.

Es acertado el criterio de Anthony Giddens, para quien es necesario un nuevo internacionalismo que mire la globalización como una realidad que nos impone mayor dependencia mutua. 
1. Diccionario de la Lengua Española. Real Academia Española, Vigésima segunda edición. Octubre de 2001.

2. Enciclopedia de la Política, Rodrigo Borja Cevallos, Fondo de Cultura Económica. México. Edición 1997.

3. Denis Duecos. La globalisation, va-t-elle unifier le monde?. Le Monde Diplomatique de agosto de 2001

4. Escuela italiana de Manciní Cantuzi, Pierantoni, etc, y pensamiento del Padre de la Patria, que en la Carta de Jamaica afirmaba que es una idea grandiosa pretender formar de todo el mundo nuevo una sola nación, con un solo vínculo que ligue sus partes entre sí y con el todo, ya que tiene un origen, una lengua, unas costumbres y una religión, debería por consiguiente tener un solo gobierno que confederase los diferentes Estados que hayan de formarse.

5. Territorios gobernados por etnarcas o gobernadores, en el bajo imperio.

6. Artículo 2, 6: La organización hará que los Estados que no son Miembros de las Naciones Unidas se conduzcan de acuerdo con estos principios en la medida que sea necesaria para mantener la paz y la seguridad internacional

7. Artículo 12: La Asamblea General podrá discutir toda cuestión relativa al mantenimiento de la paz y la seguridad internacional que presente a su consideración cualquier Miembro de las Naciones Unidas o del Consejo de Seguridad, o que un Estado que no es Miembro de las Naciones Unidas presente de conformidad con el artículo 35, párrafo 2, salvo lo dispuesto en el artículo 12, podrá hacer recomendaciones acerca de tales cuestiones al Estado o Estados interesados o al Consejo de Seguridad o a éste y a aquellos. Toda cuestión de esta naturaleza con respecto a la cual se requiera acción será referida al Consejo de Seguridad por la Asamblea General antes o después de discutirla.

8. Articulo 32: El Miembro de las Naciones Unidas que no tenga asiento en el Consejo de Seguridad o el Estado que no sea Miembro de las Naciones Unidas, si fuera parte de una controversia que esté considerando el Consejo de Seguridad, será invitado a participar sin derecho a voto en las discusiones relativas a dicha controversia. El Consejo de Seguridad establecerá las condiciones que estime justas para la participación de los Estados que no sean Miembros de las Naciones Unidas.

9. Artículo 35, 2: Un Estado que no es Miembro de las Naciones Unidas podrá llevar a la atención del Consejo de Seguridad o de la Asamblea General toda controversia en que sea parte si acepta de antemano, en lo relativo a la controversia, las obligaciones de arreglo pacífico establecido en la Carta.

10. Artículo 50: Si el Consejo de Seguridad tomare medidas preventivas o coercitivas contra un Estado, cualquier otro Estado, sea o no Miembro de las Naciones Unidas, que confrontare problemas económicos especiales originados por la ejecución de dichas medidas, tendrá el derecho de consultar al Consejo de Seguridad acerca de la solución de esos problemas.

11. Artículo 93, 2: Un Estado que no sea Miembro de las Naciones Unidas podrá llegar a ser parte en el Estatuto de la Corte Internacional de Justicia, de acuerdo con las condiciones que determine en cada caso la Asamblea General a recomendación del Consejo de Seguridad.

12. El Pacto de la Sociedad de las Naciones contenía una disposición similar (Art.16 y 17).

13. Polonia (Estado Miembro) contra España (Estado no Miembro), en el Consejo de Seguridad, acusando que las actividades del gobierno de Franco constituían una amenaza a la seguridad internacional, y solicitando la aplicación del artículo 2, 6; Litigio del estrecho de Corfú, entre Gran Bretaña (Estado Miembro) y Albania (Estado no Miembro); Problemas respecto a los derechos humanos en Bulgaria y Hungría y a los relacionados con las fronteras griegas, la cuestión palestina, el conflicto vietnamita, etc. Casos citados por Ahmed Mahiou, profesor en la Universidad de Algeria, Miembro de la Comisión de Derecho Internacional de la ONU. Comentario al parágrafo 6 del artículo 2 de la Carta. La Charte des Nations Unies, commentaire article par article, sous la direction de Jean-Pierre Cot et Alain Pellet Economica-Bruylant, 1985.

14. Ahmed Mahiou, Profesor en la Universidad de Algeria, Miembro de la Comisión de Derecho Internacional de la ONU, en un comentario al parágrafo 6 del artículo 2 de la Carta. La Charte des Nations Unies, commentaire article par article, sous la direction de Jean-Pierre Cot et Alain Pellet Economica-Bruylant, 1985. 
15. Aviación, télex, fax, internet, televisión, telefonía, comunicaciones satelitales, exploración interplanetaria.

16. No existe una sino muchas globalizaciones, por ejemplo la de la información, de las drogas, de las pestes, de la ecología y naturalmente ante todo de las finanzas. Aparece también una gran complicación porque las globalizaciones avanzan con velocidad muy diferente. Butros Butros Gali, ex Secretario general de la Organización de las Naciones Unidas.

17. La globalización ha sido definida camo el proceso de desnacionalización de los mercados, las leyes y la política. La globalización está minando o enosionando la soberanía. Ernesto Grün. Hay poderosas fuerzas de globalización actuando en el mundo moderno, que arrastran consigo al derecho. Benjamín R. Barber.

18. Unión Europea: Tratados de Libre Comercio de América del Norte, Mercosur, Comunidad Andina de Naciones, el ALCA, etc.

19. La revolución francesa identificó la soberanía con la voluntad del pueblo.

20. Enciclopedia de la Política. Rodrigo Borja Cevallos. Fondo de Cultura Económica. México. Edición 1997

21. El artículo 2, párrafo 7 de la Carta de la Organización de las Naciones Unidas dice: Ninguna disposición de esta Carta autorizará a las Naciones Unidas a intervenir en los asuntos que son esencialmente de la jurisdicción interna de los Estados, $n i$ obligará a los Miembros a someter dichos asuntos a procedimiento de arreglo conforme a la presente Carta; pero este principio no se opone a la aplicación de las medidas coercitivas prescritas en el Capítulo VII.

22. Declaración de La Habana, noviembre 18 de 1999.

23. La Declaración de las Naciones Unidas sobre la Protección de todas las personas contra las Desapariciones Forzadas establece el ejercicio de la jurisdicción universal por presuntos actos de desaparición forzada, disposición también contemplada por la Convención Interamericana sobre Desaparición Forzada de Personas.

24. La International Law Association objetó la aplicación de la jurisdicción universal con el argumento de la inmunidad soberana. 